\title{
SUSCEPTIBILIDADE DE RHYNCHOPHORUS PALMARUM À AÇÃO DE METARHIZIUM ANISOPLIAE E COMPATIBILIDADE DO ENTOMOPATÓGENO COM AGROTÓXICOS UTILIZADOS NA CULTURA DA BANANA
}

\author{
A.M.B. de Almeida ${ }^{1}$, A. Batista Filho ${ }^{1}$, H.M. Takada ${ }^{2}$, L.G. Leite ${ }^{1}$, \\ L.O. Zappelini ${ }^{1}$, I.M. Wenzel ${ }^{1}$, J.E.M. Almeida ${ }^{1}$, A.G. Carvalho ${ }^{3}$
}

${ }^{1}$ Instituto Biológico, Centro Experimental Central, CP 70, CEP 13001-970, Campinas, SP, Brasil. E-mail: amb_almeida@yahoo.com.br

RESUMO

\begin{abstract}
Este estudo teve o objetivo de selecionar isolados do fungo entomopatogênico Metarhizium anisopliae para o controle de adultos de Rhynchophorus palmarum (L.) (Coleoptera: Curculionidae) e avaliar a compatibilidade de agrotóxicos utilizados nesta cultura com o isolado que ocasionasse maior mortalidade dos adultos. Para tal, adultos do inseto foram imersos em suspensões de seis isolados do fungo na concentração de $10^{9}$ conídios. $\mathrm{mL}^{-1} \mathrm{e}$, após 24 dias, o isolado IBCB 348 causou maior mortalidade $(87,5 \%)$ e foi utilizado para o teste de compatilibidade, por meio do cálculo da fórmula de T, com inseticidas, herbicidas e fungicidas comerciais utilizados na cultura. Nenhum dos fungicidas e herbicidas testados foram compatíveis com o patógeno. Os inseticidas Calypso, Dipterex 500 e Sevin 480 SC, na concentração mínima recomendada pelo fabricante, foram os únicos produtos classificados como compatíveis com o isolado IBCB 348 de M. anisopliae.
\end{abstract}

PALAVRAS-CHAVE: Rhynchophorus palmarum, manejo integrado de pragas, fungo entomopatogênico, controle microbiano.

\begin{abstract}
SUSCEPTIBILITY OF RHYNCHOPHORUS PALMARUM TO THE ACTION OF METARHIZIUM ANISOPLIAE AND THE COMPATIBILITY OF THE ENTOMOPATHOGEN WITH AGROCHEMICALS USED IN THE BANANA CROP. This study was aimed to screen the entomopathogenic fungus Metarhizium anisopliae for the control of Rhynchophorus palmarum (L.) (Coleoptera: Curculionidae) adults and to evaluate the compatibility of agrochemicals used in this crop with the strain that caused the highest insect mortality. To this end, adult insects were immersed in suspensions of 6 strains at a concentration of $10^{9}$ conidia. $\mathrm{mL}^{-1}$, and after 24 days the isolate IBCB 348 caused the highest mortality (87.5\%) and was used in the compatibility test, using calculations by way of the $\mathrm{T}$ formula, with commercial insecticides, herbicides and fungicides used in the crop. Among the tested strains, IBCB 348 was the most efficient in the control of this pest, causing $87.5 \%$ of weevil mortality. None of the tested fungicides and herbicides were compatible with the pathogen. The insecticides Calypso, Dipterex 500 and Sevin 480 SC, at the lowest dose recommended by the manufacturer, were the only products classified as compatible with the strain IBCB 348 of M. anisopliae.
\end{abstract}

KEY WORDS: Rhynchophorus palmarum, integrated pest management, entomopathogenic fungus, microbial control.

\section{INTRODUÇÃO}

De acordo com o Brasil (2005), o Brasil produz em média 5.616.000 toneladas de banana, mas exporta apenas cerca de 3,77\% de sua produção, que corres-pondem a 212.176 toneladas. Alguns fatores colaboram para essa situação, entre os quais o baixo nível tecnológico (exceção feita para algumas regiões) e a alta incidência de pragas. A consequência é a baixa produtividade e o alto índice de perdas. Portanto, a manutenção de um bananal em boas condições sanitárias contribui para melhorar a qualidade do produto e regularizar a oferta (MASCARENHAS, 1999).

${ }^{2}$ Polo Apta do Vale do Paraíba, Pindamonhangaba, SP, Brasil.

${ }^{3}$ Casa da Agricultura de São Bento do Sapucaí, São Bento do Sapucaí, SP. Brasil 
Pragas e doenças influenciam negativamente o aspecto qualitativo e quantitativo da produção. Entre as principais preocupações estão as brocas. Recentemente, BATISTA FILHO et al. (2001) constataram a ocorrência do coleóptero Rhynchophorus palmarum atacando plantações de banana no Município de São Bento do Sapucaí, Estado de São Paulo, tradicional produtora da variedade prata (Musa sapientum). Essa espécie já foi relatada como uma importante praga nas culturas de mamão, cacau, cana-de-açúcar, coco e outras palmáceas no México e na América Central. No Brasil não havia nenhuma referência sobre esse inseto causando prejuízo em plantações comerciais de banana, fato observado em São Bento do Sapucaí. Ressalta-se que esse município concentra, aproximadamente, 300 produtores da fruta e que tem na banana uma das principais atividades econômicas da região, caracterizada pelo sistema de agricultura familiar (BATISTA FiLHO et al., 2002).

As informações existentes sobre o inseto são baseadas em trabalhos desenvolvidos, principalmente, em plantações de coqueiro (Moura et al., 1991; SANCHEs et al., 1993; FerReira et al., 1998). Na bananeira, BATISTA FiLHo et al. (2001) observaram que a quantidade de larvas foi responsável por extensas galerias no rizoma, provocando o amarelecimento da folha, redução de peso e número de cachos e queda das plantas.

Oconhecimento da compatibilidade dos produtos fitossanitários de natureza química, utilizados na cultura da banana, com potenciais entomopatógenos, é importante para a preservação desses organismos benéficos. Estudos dessa natureza são fundamentais e fornecem subsídios para o estabelecimento de uma proposta de manejo integrado desse inseto-praga para aquela região.

Assim, o objetivo deste trabalho foi o de selecionar isolados de Metarhizium anisopliae para o controle de Rhynchophorus palmarum e avaliar também a compatibilidade do entomopatógeno com agrotóxicos utilizados na cultura da banana.

\section{MATERIAL E MÉTODOS}

Coleta dos adultos no campo - Os insetos foram capturados em plantações comerciais de banana, variedade Prata, localizadas no Município de São Bento do Sapucaí, SP. As coletas de adultos foram feitas com o uso de armadilhas produzidas com baldes de $40 \mathrm{~L}$, cujas tampas foram perfuradas em dois pontos nos quais foram acoplados funis que permitia a entrada dos insetos adultos e impedia sua saída. No interior dos baldes foram colocados pedaços de toletes de cana-de-açúcar, que serviram como atrativo e, na parte superior interna da tampa, um sachê contendo feromônio. A vistoria e a coleta dos insetos foram realizadas a cada 15 dias, sendo que os adultos foram acondicionados em recipientes contendo pseudocaule de bananeira e encaminhados para o Laboratório de Controle Biológico do Centro Experimental Central do Instituto Biológico, localizado no Município de Campinas, SP. Quando necessário foi realizada a troca dos atrativos.

Seleção de isolados - A seleção foi realizada em dois experimentos no Laboratório de Controle Biológico e os isolados utilizados são provenientes da Coleção de Entomopatógenos "Odemar Cardim de Abreu" do Instituto Biológico (Tabela 1).

Tabela 1 - Origem dos isolados de M. anisopliae utilizados para o controle de $R$. palmarum.

\begin{tabular}{lcc}
\hline Isolado & Hospedeiro & Local de coleta \\
\hline IBCB 103 & Percevejo-castanho & Campinas, SP \\
IBCB 104 & Percevejo-castanho & Campinas, SP \\
IBCB 348 & Mahanarva fimbriolata & Sertãozinho, SP \\
IBCB 376 & - & - \\
IBCB 410 & Lagarta & Iporanga, SP \\
IBCB 425 & Lagarta & Iporanga, SP \\
\hline
\end{tabular}

O primeiro ensaio foi representado por quatro tratamentos: testemunha, IBCB 348, IBCB376 e IBCB 425 e no segundo foram feitos cinco tratamentos: testemunha, IBCB 103, IBCB 104, IBCB 410 e IBCB 425 divididos em quatro repetições com quatro insetos, num total de 16 . O isolado IBCB 425 repetiu-se, pois foi utilizado como isolado padrão. Para ambos os testes, os fungos foram repicados em placas de Petri de $9 \mathrm{~cm}$ de diâmetro e espalhado com alça de Drigalsky contendo meio batata-dextrose-ágar (B.D.A.). As placas foram mantidas em câmaras para germinação (B.O.D.) a $25^{\circ} \mathrm{C} \pm 0,5$ e com 12 horas de fotoperíodo, por um período de 15 dias. Após esse tempo, os conídios foram raspados das placas e colocados em água estéril.

Nos dois testes os coleópteros foram imersos na suspensão do fungo na concentração de $10^{9}$ conídios. $\mathrm{mL}^{-1} \mathrm{e}$ a testemunha em água destilada. Os adultos foram colocados em recipientes de plástico contendo pedaços de colmo de cana-de-açúcar como fonte de alimento. Os recipientes foram mantidos em sala climatizada com temperatura de $25^{\circ} \mathrm{C}$ e fotofase de 12 horas. As avaliações foram feitas a cada quatro dias totalizando seis avaliações ao longo de 24 dias. Os insetos mortos foram retirados e colocados em placas de Petri com $9 \mathrm{~cm}$ de diâmetro e um pedaço de algodão úmido. Estas foram colocadas em B.O.D. para confirmar a morte pela ação do patógeno.

Compatibilidade - A avaliação da compatibilidade foi realizada utilizando-se 20 agrotóxicos recomendados pela AGÊNCIA dE VIGILÂNCIA SANITÁRIA 
(2005) para a cultura da banana nas dosagens recomendadas pelos fabricantes (Tabela 2), com o isolado IBCB 348 de M. anisopliae.

$O$ fungo foi inicialmente repicado em meio batatadextrose-ágar (B.D.A.) e incubado a $24^{\circ} \mathrm{C}$ e fotofase de 12 horas, por sete dias, para obter-se uma placa matriz.

Após a esporulação do fungo, $150 \mathrm{~mL}$ de meio de cultura(B.D.A.) foram autoclavadose, ao atingir a temperatura de aproximadamente $45^{\circ} \mathrm{C}$, ou seja, antes da solidificação, adicionou-se os produtos fitossanitários. Em seguida, a mistura foi vertida em placas de Petri de $9 \mathrm{~cm}$ de diâmetro, sendo três placas para cada concentração de agrotóxicos. $\mathrm{O}$ tratamento testemunha foi representado pelo meio de cultura específico sem aplicação de agrotóxicos. Após solidificação do meio, o fungo foi repicado em três pontos das placas por meio de uma alça de platina, totalizando, para cada tratamento, seis colônias provenientes de duas placas de Petri. As placas foram mantidas em câmaras para germinação (B.O.D.) a $24^{\circ} \mathrm{C} \pm 0,5$ com 12 horas de fotoperíodo, incubadas durante 15 dias.

Para avaliação da compatibilidade foram considerados o tamanho da colônia (crescimento vegetativo), o número de conídios produzidos (esporulação) e a viabilidade desses conídios.

Ocrescimento vegetativo das colônias foi avaliado por meio do diâmetro médio da colônia, obtido por duas medições perpendiculares. Para contagem do número de conídios, as três colônias de cada placa foram recortadas do meio de cultura. O material foi transferido para tubos de ensaio $(8,5 \mathrm{~cm}$ de altura e 2,5 cm de diâmetro) com $10 \mathrm{~mL}$ de água destilada estéril mais espalhante adesivo $0,1 \%$ (Tween $80 \AA$ ) e as suspensões diluídas do micro-organismo foram analisadas em câmara de Neubauer.

A viabilidade dos conídios, foi avaliada através do plaqueamento das suspensões fúngicas em placas de Petri contendo B.D.A e incubação por 15 horas a $24^{\circ} \mathrm{C}$ e 12 horas de fotofase.

Além disso, calculou-se o fator de compatibilidade(Valor "T"), proposto por Alvesetal. (1998), que permitiu a separação dos produtos em classes de seletividade/compatibilidade, de acordocomoefeito observado em relação aos parâmetros avaliados. $\mathrm{O}$ cálculo desse índice foi feito por meio da fórmula:

$$
\mathrm{T}=20[C V]+80[E S P] / 100
$$

Onde:

$\mathrm{T}=$ valor corrigido para classificação do produto; $\mathrm{CV}=$ porcentagem de crescimento vegetativo em relação à testemunha;

$\mathrm{ESP}=$ porcentagem de esporulação (conidiogênese) em relação à testemunha.

Os valores calculados de " $\mathrm{T}$ " foram comparados com os seguintes limites estabelecidos: 0 a $30=$ muito tóxico; 31 a $45=$ tóxico; 46 a $60=$ moderadamente tóxico e $>60=$ compatível.

Tabela 2 - Agrotóxicos e respectivas concentrações recomendadas pelo fabricante utilizados no teste de compatibilidade com M. anisopliae.

\begin{tabular}{|c|c|c|}
\hline Marca comercial & \multirow{2}{*}{ Ingrediente ativo } & \multirow{2}{*}{ Concentração recomendada } \\
\hline Fungicidas & & \\
\hline Bayfidan 60 GR & triadimenol & $100 \mathrm{~mL} / \mathrm{ha}$ \\
\hline Bravonil 500 & clorotalonil & $1,0-2,0$ Lha \\
\hline Cercobin 700 PM & tiofanato-metílico & $300-400 \mathrm{~g} / \mathrm{ha}$ \\
\hline Cobre Sandoz BR & óxido cuproso & $180 \mathrm{~g} / 100$ L de água \\
\hline Comet & piraclostrobina & $0,4 \mathrm{~L} / \mathrm{ha}$ \\
\hline Condor $200 \mathrm{CE}$ & bromuconazol & $600 \mathrm{~mL} / \mathrm{ha}$ \\
\hline Cupravit Azul & oxicloreto de cobre & 300 g/100L de água \\
\hline Cuprozeb & Mancozebe + oxicloreto de cobre & 250 g/100L de água \\
\hline Folicur $200 \mathrm{CE}$ & tebuconazol & $0,5 \mathrm{~L} / \mathrm{ha}$ \\
\hline Opus & epoxiconazol & $0,4 \mathrm{~L} / \mathrm{ha}$ \\
\hline Persist SC & mancozebe & $4,5 \mathrm{~L} / \mathrm{ha}$ \\
\hline \multicolumn{3}{|l|}{ Inseticidas } \\
\hline Calypso & tiacloprido & 40 mL/100 L de água \\
\hline Dipterex 500 & triclorfom & 300 mL/ 100 L de água \\
\hline Iharol & óleo mineral & $0,5 \mathrm{~L} / \mathrm{ha}$ \\
\hline Piritilen & clorpirifós & $0,5 \mathrm{~L} / \mathrm{ha}$ \\
\hline Sevin $480 \mathrm{SC}$ & carbaril & 225-340 mL/100L de água \\
\hline \multicolumn{3}{|l|}{ Herbicidas } \\
\hline Cention SC & diurom & $2,5-4 \mathrm{~L} / \mathrm{ha}$ \\
\hline Finale & glufosinato-sal de amônio & $2,0 \mathrm{~L} / \mathrm{ha}$ \\
\hline Gramoxone 200 & dicloreto de paraquate & $1,5-3,0 \mathrm{~L} / \mathrm{ha}$ \\
\hline Roundup WG & glifosato & $0,5-6,0 \mathrm{~L} / \mathrm{ha}$ \\
\hline
\end{tabular}


Análise estatística - Os dados obtidos foram submetidos à análise de variância pelo teste $\mathrm{F}$ e ao teste de Tukey para comparação entre as médias, utilizando-se o programa Estat (1997).

\section{RESULTADOS E DISCUSSÃO}

Seleção de isolados - Observou-se que o isolado IBCB 348 foi o mais patogênico aos adultos de R. palmarum, apresentando $87,5 \%$ de mortalidade confirmada dos insetos. Este isolado não diferiu estatisticamente dos isolados IBCB 376, IBCB 425, IBCB 104 e IBCB 410 , causando respectivamente, $75 \%, 75 \%$, $56,25 \%$ e $43,75 \%$ de mortalidade confirmada dos adultos. O isolado IBCB103 e a testemunha não diferiram estatisticamente entre si, apresentando $31,25 \%$ e $0 \%$ de mortalidade confirmada pelo patógeno (Fig. 1).

Apesar do controle de coleópteros ser usualmente estudado com o fungo entomopatogênico Beauveria bassiana, muitos autores vêm pesquisando o uso de M. anisopliae para o controle desses insetos.

WENZEL et al. (2003) utilizaram o isolado IBCB 348 de M. anisopliae e obtiveram morte de $27 \%$ dos adultos de R. palmarum ao fazer os insetos caminharem sobre arroz colonizado pelo patógeno. Já
TAKADA (2002) obteve $52 \%$ e $85,3 \%$ de mortalidade de adultos do curculionídeo Oryzophagus oryzae, com os isolados IBCB 103 e IBCB 104 considerando-os isolados promissores para o controle do inseto.

POтRIcH et al. (2006), fazendo uma seleção de isolados das duas espécies fúngicas, obtiveram o isolado Unioeste 22 de $M$. anisopliae que causou a mortalidade de $65 \%$ de adultos do também curculionídeo Sitophilus zeamays.

Por outro lado, ROHDE et al. (2006), utilizando os isolados avaliados neste estudo, IBCB 104, IBCB 348 eIBCB 425, não encontraram resultados satisfatórios para o controle de adultos de Alphitobius diaperinus, mas obtiveram controle de $63,3 \%$ e $86 \%$, utilizando os isolados IBCB 104 e IBCB 348 respectivamente, no controle das larvas do inseto, assim como ALEXANDRE et al. (2006) que obtiveram níveis acima de $80 \%$ de controle de larvas deste inseto utilizando os isolados UEL 50 e IBCB 116 de M. anisopliae, mostrando maior susceptibilidade das larvas de coleópteros ao entomopatógeno do que os adultos.

Nesteestudo, ocontrole com oisoladoIBCB348 foi bastante satisfatório em adultos, que é a forma mais fácil de ser controlada em uma situação de campo, já que as larvas (provavelmente mais susceptíveis) se instalam dentro do colmo da banana, dificultando a aplicação de M. anisopliae.

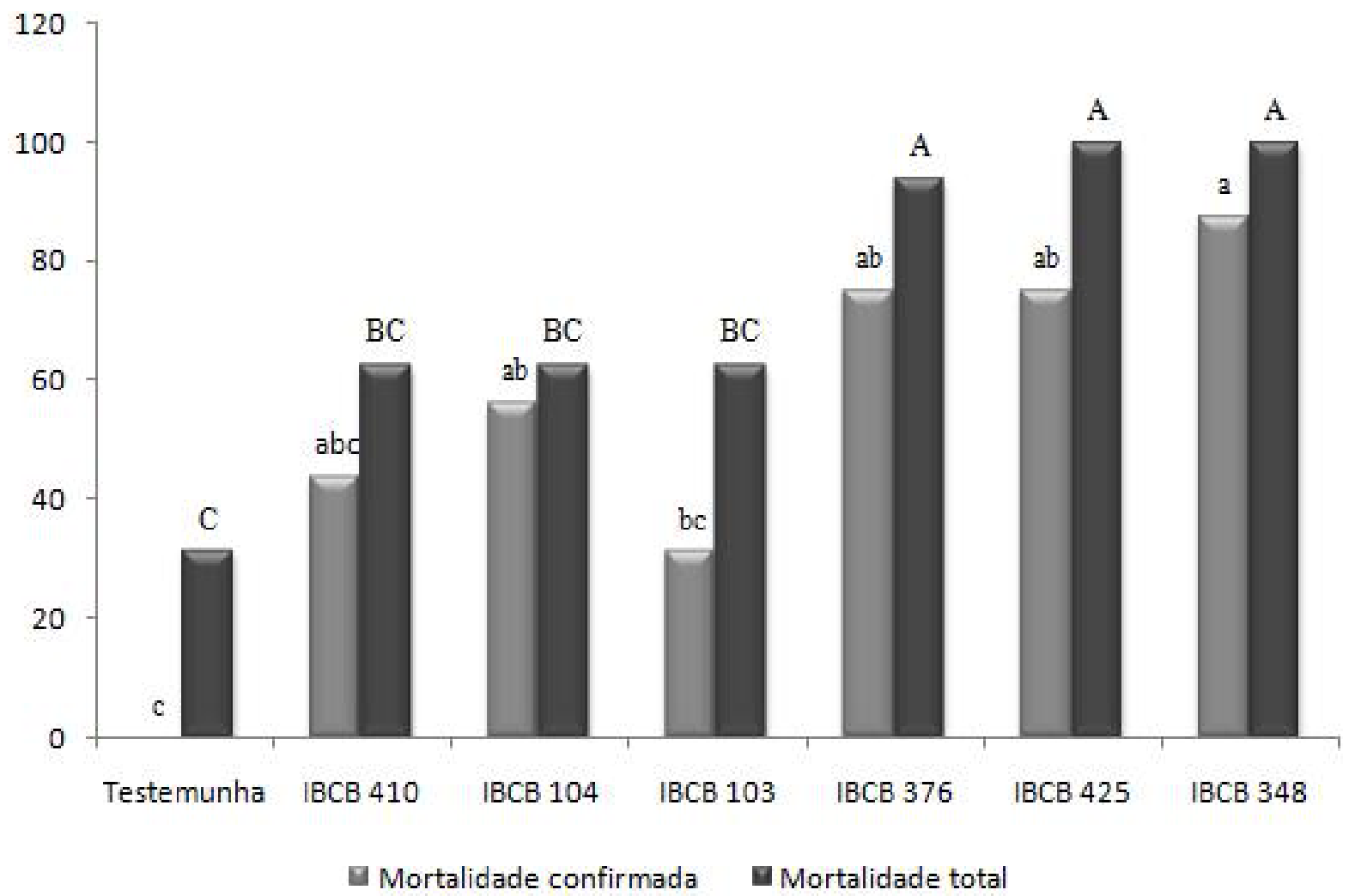

Fig. 1 - Mortalidades total e confirmada de adultos de Rhynchophorus palmarum dos diferentes isolados de Metarhizium anisopliae. Médias seguidas de mesma letra não diferem entre si pelo teste Tukey a 5\% de probabilidade. 
Tabela 3 - Médias do diâmetro das colônias, número e viabilidade dos conídios de M. anisopliae em função dos tratamentos ( $\mathrm{T}=24^{\circ} \mathrm{C}$, fotofase de 12 horas).

\begin{tabular}{|c|c|c|c|}
\hline Tratamentos & Diâmetro $(\mathrm{cm})^{*}$ & Conídios $\left(\times 10^{8}\right)^{* 1}$ & Viabilidade $(\%)^{*}$ \\
\hline Testemunha & 4,08 a & 1,13 a & 85,33 a \\
\hline Cupravit Azul & $3,07 \quad b$ & $0,71 \quad b$ & 80,83 a \\
\hline Cuprozeb & 1,17 & 0 & $\begin{array}{ll}0 & b\end{array}$ \\
\hline Folicur $200 \mathrm{CE}$ & $0,00 \quad \mathrm{~d}$ & $0 \quad \mathrm{c}$ & $0 \quad b$ \\
\hline Teste F & $297,22^{* *}$ & $118,87^{* *}$ & $691,01^{* *}$ \\
\hline C.V. $(\%)$ & 12,54 & 4,89 & 10,77 \\
\hline Tratamentos & Diâmetro (cm) & Conídios $\left(x 10^{8}\right)^{1}$ & Viabilidade (\%) \\
\hline Testemunha & 3,97 a & 1,160 a & 86,00 a \\
\hline Bayfidan 60 GR & $1,35 \quad b$ & $0,031 \quad b$ & $1,75 \quad b$ \\
\hline Cercobin 700 PM (mín) & 0,00 & 0,000 & 0,00 \\
\hline Cercobin 700 PM (máx) & $0,00 \quad c$ & $0,000 \quad b$ & $0,00 \quad b$ \\
\hline Teste F & $271,19^{* *}$ & $116,47^{* *}$ & $2097,84^{* *}$ \\
\hline C.V. $(\%)$ & 20,94 & 3,97 & 10,41 \\
\hline Tratamentos & Diâmetro $(\mathrm{cm})$ & Conídios $\left(\times 10^{8}\right)^{1}$ & Viabilidade (\%) \\
\hline Testemunha & 4,14 a & 0,80 a & $84,83 \quad \mathrm{~b}$ \\
\hline Dipterex 500 & $3,82 \quad b$ & $0,46 \quad b$ & 94,50 a \\
\hline Iharol & $2,78 \quad c$ & $0,25 \quad c$ & 89,08 a b \\
\hline Piritilen & $0,84 \quad \mathrm{~d}$ & $0,00 \quad c$ & $0,00 \quad c$ \\
\hline Teste F & $535,39^{* *}$ & $331,36^{* *}$ & $767,05^{\text {** }}$ \\
\hline C.V. $(\%)$ & 5,46 & 1,87 & 5,92 \\
\hline Tratamentos & Diâmetro $(\mathrm{cm})$ & Conídios $\left(\times 10^{8}\right)^{1}$ & Viabilidade (\%) \\
\hline Testemunha & 4,34 a & 1,47 a & 86,9 a \\
\hline Condor $200 \mathrm{CE}$ & $0,00 \quad c$ & $\begin{array}{ll}0 & b\end{array}$ & $0,0 \quad b$ \\
\hline Finale & $0,83 \quad b$ & $0,0009 \quad b$ & 0,0 \\
\hline Gramoxone 200 (mín) & $0,00 \quad c$ & 0 & 0,0 \\
\hline Gramoxone 200 (máx) & $0,00 \quad \mathrm{c}$ & $0 \quad b$ & $0,0 \quad b$ \\
\hline Teste F & $1194,53^{* *}$ & 119,79 ** & $6723,42^{* *}$ \\
\hline C.V. $(\%)$ & 12,9 & 5,11 & 6,68 \\
\hline Tratamentos & Diâmetro $(\mathrm{cm})$ & Conídios $\left(\times 10^{8}\right)^{1}$ & Viabilidade (\%) \\
\hline Testemunha & 4,57 a & 0,73 a & 79,5 a \\
\hline Bravonil 500 (min) & $1,90 \quad \mathrm{c}$ & 0,0031 & $0,0 \quad b$ \\
\hline Bravonil 500 (max) & 1,17 & 0,00038 & $0,0 \quad b$ \\
\hline Calypso & 4,37 a & 1,00 a & 77,1 a \\
\hline Cobre Sandoz BR & 4,39 a & $0,30 \quad b$ & 80,4 a \\
\hline Persist SC & 0,00 & 0 & $0,0 \quad b$ \\
\hline Roundup WG (min) & $3,14 \quad b$ & 0,20 & 77,0 a \\
\hline Roundup WG (máx) & $0,44 \quad \mathrm{e}$ & $\begin{array}{ll}0 & \mathrm{C}\end{array}$ & $0,0 \quad \mathrm{~b}$ \\
\hline Teste F & $1258,99^{* *}$ & $47,20^{\star *}$ & $655,89 * *$ \\
\hline C.V. $(\%)$ & 5,15 & 19,14 & 10,23 \\
\hline Tratamentos & Diâmetro $(\mathrm{cm})$ & Conídios $\left(x 10^{8}\right)^{1}$ & Viabilidade (\%) \\
\hline Testemunha & 4,65 a & 1,550 a & 85,75 a \\
\hline Cention SC (mín) & $2,08 \quad b c$ & $0,021 \quad b$ & $26,66 \quad b$ \\
\hline Cention SC (máx) & 1,95 & 0,006 & 25,91 \\
\hline Comet & 0,00 & 0,000 & 0,00 \\
\hline Opus & $0,00 \quad d$ & 0,000 & $0,00 \quad c$ \\
\hline Sevin 480 SC (mín) & $2,20 \quad b$ & 0,004 & $25,00 \quad b$ \\
\hline Sevin 480 SC (máx) & $2,01 \quad c$ & $0,002 \quad b$ & $0,00 \quad c$ \\
\hline Teste F & $1536,51^{* *}$ & $133,02^{* *}$ & $656,40^{* *}$ \\
\hline C.V. $(\%)$ & 5,34 & 4,37 & 12,46 \\
\hline
\end{tabular}

*Médias seguidas de mesma letra na coluna não diferem entre si pelo Teste de Tukey a 5\% de probabilidade.

** significativo a $1 \%$ de probabilidade pelo Teste C.V. = Coeficiente de Variação.

${ }^{1}$ Dados transformados por $\sqrt{x+1}$.

Compatibilidade - Dentre os produtos testados, Cercobin700 PM, Cuprozebe Folicur 200 CE afetaram o crescimento vegetativo das colônias do fungo e não permitiram a sua esporulação. Já o produto Cupravit 
Azul, afetou moderadamente o diâmetro das colônias e a esporulação, mantendo sua viabilidade em valor alto, não diferindo estatisticamente da testemunha (Tabela 3). Li; Holdom (1994) observaram que há maior tolerância de M. anisopliae à inseticidas e herbicidas do que aos fungicidas, como o encontrado no presente estudo. O herbicida Gramoxone 200 inibiu completamente o crescimento das colônias, este resultado é semelhante ao desses autores que observaram queGramoxone afetou moderadamente o crescimento das colônias de M. anisopliae, mas não permitiu esporulação.

O herbicida Cention SC, em suas duas dosagens, afetou o crescimento das colônias e afetou bastante a esporulação das mesmas. Li; Holdom (1994) observaram que a molécula deste produto não permitiu o crescimento e a esporulação de um isolado de $M$. anisopliae, mas afetou o desenvolvimento dos outros três isolados testados.

Os fungicidas Condor $200 \mathrm{CE}$, Comet, Opus e Persist SC inibiram completamente o crescimento das colônias (Tabela 3) e foram classificados como muito tóxicos ao patógeno. Mochi et al. (2005) testando a ação de agrotóxicos a M. anisopliae no solo observaram que mancozebe (molécula de PersistSC) afetou a sobrevivência do fungo. Esta molécula, se encontra no grupo dos fungicidas protetores, que apresentam atividades em múltiplos sítios de ação afetando o processo de vários fungos fitopatogênicos (GHini; Kimati, 2000), podendo explicar assim essa inibição do entomopatógeno $M$. anisopliae.

O fungicida Bravonil 500, nas duas dosagens afetou, o crescimento e permitiu baixa esporulação do fungo, assim com Roundup WG que chegou a inibir a esporulação na maior dosagem utilizada. Mochi et al. (2005) observaram que clorotalonil inibe a atividade respiratória do fungo no solo, assim como Roundup, mas esses resultados diferem de Alves et al. (2000) que classificaram o herbicida como compatível ao patógeno em citros. Essa diferença entre os resultados, provavelmente deve-se à diferença das dosagens utilizadas nos estudos, visando controle de insetos de diferentes culturas.

Quanto à toxicidade dos produtos ao fungo, o fungicida Cupravit Azul foi classificado como moderadamente tóxico ao fungoe Bayfidan 60GR, Cercobin 700 PM, Condor 200 CE, Cuprozeb, Finale, Folicur 200 CE e Gramoxone 200 foram classificados como muito tóxicos ao isolado IBCB 348 de $M$. anisopliae (Tabela 4). Loureiro et al. (2002) já haviam constatado que Cercobin 700 PM e Folicur 200 CE, nas dosagens recomendadas para as culturas de crisântemoealface, inibiram completamente o crescimento vegetativo e a esporulação do isolado IBCB 425 de M. anisopliae sendo classificados como muito tóxicos ao fungo. FAION (2004) também constatou o mesmo efeito tóxico de Cercobin 700 PM para este patógeno.
Tabela 4 - Valores de T e classificação dos produtos em relação à compatibilidade de $B$. bassiana e $M$. anisopliae

\begin{tabular}{|c|c|c|}
\hline \multirow{2}{*}{$\begin{array}{l}\text { Tratamento } \\
\text { Fungicidas }\end{array}$} & \multicolumn{2}{|c|}{ M. anisopliae } \\
\hline & Valor de $\mathrm{T}$ & Classificação \\
\hline Bayfidan 60 GR & 6,95 & MT \\
\hline Bravonil 500 (min) & 8,59 & MT \\
\hline Bravonil 500 (max) & 5,15 & MT \\
\hline Cercobin 700 PM (mín) & 0 & MT \\
\hline Cercobin 700 PM (máx) & 0 & MT \\
\hline Condor $200 \mathrm{CE}$ & 0 & MT \\
\hline Cobre Sandoz BR & 43,48 & $\mathrm{~T}$ \\
\hline Comet & 0 & MT \\
\hline Cupravit Azul & 54,97 & $\mathrm{MC}$ \\
\hline Cuprozeb & 0,55 & MT \\
\hline Folicur $200 \mathrm{CE}$ & 0 & $\mathrm{MT}$ \\
\hline Opus & 0 & MT \\
\hline Persist SC & 0 & MT \\
\hline \multicolumn{3}{|l|}{ Inseticidas } \\
\hline Calypso & 86,24 & $\mathrm{C}$ \\
\hline Dipterex 500 & 64,46 & $\mathrm{C}$ \\
\hline Iharol & 38,42 & $\mathrm{~T}$ \\
\hline Piritilen & 4,05 & MT \\
\hline Sevin 480 SC (mín) & 9,67 & $\mathrm{C}$ \\
\hline Sevin 480 SC (máx) & 8,74 & MT \\
\hline \multicolumn{3}{|l|}{ Herbicidas } \\
\hline Cention SC (mín) & 10,02 & MT \\
\hline Cention SC (máx) & 8,74 & MT \\
\hline Finale & 3,87 & MT \\
\hline Gramoxone 200 (mín) & 0 & MT \\
\hline Gramoxone 200 (máx) & 0 & MT \\
\hline Roundup WG (mín) & 21,91 & MT \\
\hline Roundup WG (máx) & 1,92 & MT \\
\hline
\end{tabular}

O inseticida Iharol afetou moderamente o crescimento vegetativo das colônias do fungo e permitiu média esporulação do mesmo (Tabela 3), assim como o observado por SiLva et al. (2006), sendo classificado como tóxico à M. anisopliae (Tabela 4). Dipterex 500 foi classificado como compatível ao isolado IBCB 348 (Tabela 4), corroborando dados com TANZINI et al. (2002) que constataram que este produto é compatível ao isolado 1189 de M. anisopliae.

O inseticida Piritilen foi classificado como muito tóxico ao entomopatógeno permitindo baixo cresci- 
mento vegetativo e nenhuma esporulação do fungo. PACHAMUthu et al. (1999) também observaram que seu ingrediente ativo afetou o crescimento vegetativo de colônias de M. anisopliae.

Ressalta-se que com a grande quantidade de produtos que foram classificados como incompatíveis aos dois patógenos, há a necessidade de realizar experimentos de compatibilidade em campo com estes, pois, nas condições in vitro desses experimentos, o micro-organismo fica exposto ao máximo à ação do produto, o que não ocorre em campo, já que vários fatores protegem o micro-organismo. Assim, quando o produto é classificado como compatível ao entomopatógeno, não há necessidade de repetir os experimentos em campo, mas quando ocorre o contrário deve-se repetir, pois nem sempre os testes in vitro sugerem a real toxicidade em campo (Alves et al., 2000).

\section{CONCLUSÕES}

OisoladodeIBCB348de M. anisopliae é patogênico à R. palmarum e pode ser utilizado em conjunto com os inseticidas Calypso, Dipterex 500 e Sevin 480 SC que, na concentração mínima, são compatíveis com $\mathrm{o}$ isolado.

\section{AGRADECIMENTOS}

À Fundação de Amparo à Pesquisa do Estado de São Paulo pela bolsa de iniciação científica concedida à primeira autora e à $\mathrm{PqC}$ Msc. Harumi Hojo do Centro de Pesquisa e Desenvolvimento de Sanidade Vegetal do Instituto Biológico pelo fornecimento dos produtos utilizados.

\section{REFERÊNCIAS}

AGÊNCIA NACIONAL DE VIGILÂNCIA SANITÁRIA (Brasil) Disponível em: <http://www4.anvisa.gov.br/ AGROSIA/asp/frm_pesquisa_agrotoxico.asp $>$. Acesso em: 15 jan. 2005.

ALEXANDRE, T.M.; ALVES, L.F.A.; NEVES, P.M.O.J;; ALVES, S.B. Efeito da temperatura e cama do aviário na virulência de Beauveria bassiana (Bals.) Vuill. e Metarhizium anisopliae (Metsch.) para o controle do cascudinho (Alphitobius diaperinus) (Panzer) (Coleoptera:

Tenbrionidae). Neotropical Entomology, v.35, n.1, p.75-82, 2006.

ALVES, S.B.; MOINO JUNIOR, A.; ALMEIDA.; J.E.M. Produtos fitossanitários e entomopatógenos. In: (Ed.). Controle microbiano de insetos.

2.ed. Piracicaba: FEALQ, 1998. 1163p. Cap. 8.
ALVES, S.B.; LOPES, R.B.; TAMAI, M.A.; MOINO JUNIOR, A.; ALVES, L.F.A. Compatibilidade de produtos fitossanitários com entomopatógenos em citros. Laranja, v.21, n.2, p.289-294, 2000.

BATISTA FILHO, A.; TAKADA, H.M.; CARVALHO, A.G.; ALMEIDA, J.E.M.; LEITE, L.G.; IDE, S. Ocorrência e danos de Rhynchophorus palmarum (L.) (Coleoptera: Curculionidae) em plantações de banana em São Bento do Sapucaí, Estado de São Paulo. Arquivos do Instituto Biológico, São Paulo, v.68, p.46, 2001. Suplemento. Trabalho apresentado na REUNIÃO ANUAL DO INSTITUTO BIOLÓGICO, 2001, 14., São Paulo. Resumo 039.

BATISTA FILHO, A.; TAKADA, H.M.; CARVALHO, A.G. Brocas da bananeira. In: REUNIÃO ITINERANTE DE FITOSSANIDADE DO INSTITUTO BIOLÓGICO, 7., São Bento do Sapucaí, SP. Anais. São Bento do Sapucaí: 2002. p.1-16.

BRASIL. Ministério da Agricultura, Pecuária e Abastecimento. Agricultura Brasileira em números. Anuário 2005. Disponível em: <http:/ / www.agricultura.gov.br>. Acesso em: 8 dez. 2006.

ESTAT - Sistema de análises estatísticas. v.20 (livre). Jaboticabal, SP: FCAV/Unesp, 1997. Disponível em: <http://www.fcav.unesp.br/download2/softweres/ estat/>. Acesso em: 15 jan. 2005.

FAION, M. Toxicidade de agrotóxicos utilizados no controle de Bemisia tabaci biótipo B, sobre fungos entomopatogênicos. 2004. 86 p. Dissertação (Mestrado - Entomologia) - Escola Superior de Agricultura “Luiz de Queiroz" Universidade de São Paulo, Piracicaba, 2004. Disponível em: <http://www.teses.usp.br/teses/disponiveis/11/11146/ide-02052005-140047/>. Acesso em: 27 ago. 2005.

FERREIRA, J.M.S.; LIMA, M.F.; SANTANA, D.L.Q.; MOURA, J.I.L. Pragas do coqueiro. In:

(Ed.). Pragas de fruteiras tropicais de importância agroindustrial. Brasília: EMBRAPA-SPI, 1998. 209p.

GHINI, R.; KIMATI, H. (Ed.). Resistência de fungos a fungicidas. Jaguariúna: Embrapa Meio Ambiente, 2000. $78 \mathrm{p}$.

LI, D.P.; HOLDOM, D.G. Effects os Pesticides on Frowth and Sporulation of Metarhizium anisopliae (Deuteromycotina: Hyphomycetes). Journal of Invertebrate Pathology, v.63, p.209-211, 1994.

LOUREIRO, E.S.; MOINO JUNIOR, A.; ARNOSTI, A.; SOUZA, G.C. Efeito de produtos fitossanitários químicos utilizados em alface e crisântemo sobre fungos entomopatogênicos. Neotropical Entomology, v.31, n.2, p.263-269, 2002.

MASCARENHAS, G.C.C. Pragas da bananeira. Informe agropecuário EPAMIG, v.20, n.196, p.97-108, 1999. 
MOCHI, D.A.; MONTEIRO, A.C.; BARBOSA, J.C. Action of pesticides to Metarhizium anisopliae in soil. Neotropical Entomology, v.34, n.6, p.961-971, 2005.

MOURA, J.I.L.; RESENDE, M.L.V.; LIMA, M.F.; SANTANA, D.L.Q. Táticas para o controle integrado de Rhynchophorus palmarum (L.) (Coleoptera: Curculionidae). Ilhéus: CEPLAC, 1991. 16p.

PACHAMUTHU, P.; KAMBLE, S.T.; YUEN, G.Y. Virulence of Metarhizium anisopliae (Deuteromycotina: Hyphomycetes) strain ESC-1 to the German cockroach (Dictyoptera: Blatellidae) and its compatibility with insecticides. Journal of Economic Entomology, v.92, n.2, p.340-346, 1999.

POTRICH, M.; ALVES, L.F.A.; MERTZ, N.R.; SILVA, E.R.L. da Avaliação de Beauveria bassiana (Bals.) Vuill. E Metarhizium anisopliae (Metsch.) Sorok. Para Controle de Sithophilus zeamais (Coleoptera: Curculionidae). BioAssay, v.1, n.2, p.1-9, 2006.

ROHDE, C.; ALVES, L.F.A.; NEVES, P.M.O.J.; ALVES, S.B.; SILVA, E.R.L. da; ALMEIDA, J.E.M. Seleção de Isolados de Beauveria bassiana (BAls.) Vuill. E Metarhizium anisopliae (Metsch.) Sorok. Contra o Cascudinho Alphitobius diaperinus (Panzer) (Coleoptera: Tenebrionidae). Neotropical Entomology, v.35, n.2, p.231-240, 2006.

SANCHES, P.A.; JAFFÉ, K.; HERNANDEZ, J.V.; CREDA, H. Biologia y comportamento del picudo del cocotero Rhynchophorus palmarum L. (Coleoptera: Curculionidae). Boletim de Entomologia Venezuelana, v.8, n.1, p.83-93, 1993.
SILVA, R.Z.; NEVES, P.M.O.; SANTORO, P.H.; CAVAGUCHI, S.A. Efeito de agroquímicos à base de óleo mineral e vegetal sobre a viabilidade dos fungos entomopatogênicos Beauveria bassiana (Bals.) Vuillemin, Metarhizium anisopliae (Metsch.) Sorokin e Paecilomyces sp. Bainier. BioAssay, v.1, n.1, p.1-5, 2006.

TANZINI, M.R.; ALVES, S.B.; SETTEN, A. Toxicidade de produtos fitossanitários utilizados no controle de Leptopharsa heveae para fungos entomopatogênicos. Arquivos do Instituto Biológico, São Paulo, v.69, n.4, p.65-69, 2002.

TAKADA, H. M. Patogenicidade e seleção de isolados de Metarhizium anisopliae (Metsch.) Sorokin e Beauveria bassiana (Bals.) Vuill. para o controle de Oryzophagus oryzae (Costa Lima, 1936) (Coleoptera: Curculionidae). 2002. $75 f$. Dissertação (Mestrado em Agronomia - Área de Proteção de Plantas) - Faculdade de Ciências Agronômicas, Universidade Estadual Paulista "Júlio de Mesquita Filho", Botucatu, 2002.

WENZEL,I.M.; BATISTA FILHO, A.; TAKADA, H.M.; CARVALHO, A.G.; LEITE, L.G.; ALMEIDA, J.E.M.; RODRIGUES, L.T.B. Avaliação da patogenicidade de isolados de Beauveria bassiana e Metarhizium anisopliae sobre adultos de Rhynchophorus palmarum (Coleoptera: Curculionidae). Arquivos do Instituto Biológico, São Paulo, v.70, p.510-512, 2003. Suplemento 2.

Recebido em 1/10/09

Aceito em 28/10/10 